\title{
Health in the System of Students' Axiological Orientations
}

\author{
Svetlana A. Mukhina ${ }^{1}$, Olga V. Polozova ${ }^{1}$, Maria N. Gavrilova ${ }^{1}$, Irina S. Zimina ${ }^{1}$, Olga A. Yagdarova ${ }^{1}$, Ivan V. \\ ${ }^{1}$ Mari State University, Yoshkar-Ola, Russia \\ Zabrodin $^{1} \&$ Valentina V. Bakhtina ${ }^{1}$ \\ Correspondence: Svetlana A. Mukhina, The Faculty of Physical Education, Sports and Tourism, Mari State \\ University, Lenin sq., 1, Yoshkar-Ola, 424000, Russia.
}

Received: February 21, 2015 Accepted: March 15, 2015 Online Published: April 29, 2015

doi:10.5539/res.v7n8p239

URL: http://dx.doi.org/10.5539/res.v7n8p239

\begin{abstract}
The timeliness of the problem at issue is determined by the presence of contradictions between modern conditions of the society which advance special requirements for the formation of the system of the personality's axiological orientations on health and by the insufficient system of work towards this problem in the educational environment. The purpose of this study was to investigate the structure of the students' orientation on a healthy lifestyle. The question of the health essence has always been the central methodological problem of many sciences including pedagogy. In this regard, education can act as an institution for improving health of the future generation. The article presents the results of the study of the structure of orientation of the students of Mari State University (future teachers) on a healthy lifestyle. 203 respondents among junior and senior students were questioned according to the V. I. Andreev's questionnaire test which determines the levels of orientation on a healthy lifestyle. The questionnaire survey showed that the correct definition of the concepts "health" and "healthy lifestyle" is given by $31 \%$ and $24 \%$ senior students, $13 \%$ and $10 \%$ junior students respectively. The principal health index is the absence of bad habits so this issue was analyzed in the article. We found out that senior students are less inclined to having bad habits than junior students. The analysis is of grading of life values showed that all the respondents had given the first three places to health, love, understanding in the family. It is necessary to note that senior students also note material wealth as one of the five most important life values. The analysis of the results shows that health takes the leading place in the system of values but only one-third of respondents give a correct definition of a healthy lifestyle. We can observe the positive dynamics in the personality's orientation on a healthy lifestyle by 4-5 years of study. In general, the data obtained reflect the average level of formedness of the cognitive and practical components of the students' axiological and orientational activity. It is necessary to form the system of use of pedagogical technologies in the field of a healthy lifestyle aimed at forming health culture of future teachers.
\end{abstract}

Keywords: health, healthy lifestyle, health saving, axiological orientations

\section{Introduction}

The formation of the axiological attitude of the person's health is the most important problem of modern times. In this process the special place is held by the system of education which is responsible, as a significant part of the society, for preparing young people for adult lifeand, eventually, creating the conditions for continuous physical, moral, spiritual and cultural improvement of the society. Modern life conditions advance raised requirements for health of children and young students. Therefore, the range of healthproblems becomes more and more urgent in the system of education. Nowadays in teaching practice we can observe the tendency for transition from mass uniform education to education focused on personality traits and abilities of each individual as well as on the level of their health.

Another stage of reforming the educational system distinguishes a "person-saving" function of education. Education must become an institution of saving and improving physical and mental health of children and young people. The educational process in high school involves not only education and upbringing of students but also improvement of their health. It is health that will determine, to a significant degree, the state of the Russian population in the XXI centuries. The health indexes of the population of the Mari El Republical lowed us to find out that, among various risk factors integrated according to the classification of the World Health Organization (WHO) into 4 groups (lifestyle, living environment, heredity and quality of medical care) it is mostly lifestyle and living environment that influence the population's health in the towns of the republic. In rural areas the 
factor of medical care development and availability level is added (State report "On the state of sanitary and epidemiological welfare", 2014).

People's health is determined by various factors: heredity, life quality, environment condition, society, medical care quality etc. Nevertheless, the opinion of academician N. M. Amosov that people's misbehavioris more common cause of their illnesses than external influences or weakness of the human nature isstillurgent. To become healthy, we must take our own efforts, constant and significant. The attitude to health is stipulated by objective circumstances including upbringing and education. It is manifested in actions and acts, opinions and judgments of people with respect to the factors affecting their physical and mental welfare. By differentiating the attitude to health into adequate (reasonable) and inadequate (careless) attitude, we can distinguish, for our purpose, two diametrically opposed types of a person's behavior with respect to the factors promoting or threatening people's health.

The degree of conformity of the person's acts and actions with the requirements for a healthy lifestyle as well as with the medicine regulatory requirements, sanitation and hygiene can serve as a criterion of the measure of adequacy of the attitude to health in behavior. In giving opinions and judgments it acts as a level of the individual's awareness and competence. The attitude to health also includes the person's self-assessment of their physical and mental state which is a kind of indicator and regulator of their behavior (URL: $\mathrm{http} / / / \mathrm{biofile.ru} / \mathrm{chel} / 14665 . \mathrm{html}$ (accessed date: 20.10.2014)). To form the attitude to health as to the foremost value, give the knowledge of human health necessary for each individual's life, teach to lead a regular life (or thobiosis - according to I. I. Mechnikov) is the task of human is ticpedagogy.

When considering the state of health taking into account the reasons and factors that determine it, it is important to understand that there are two levels of health: social and individual. Social, or populational, health reflects general trends in the change in health of the population of the country, region, settlement. Individual health is health of particular people (Shabunova, 2010).

Health is the natural, absolute and on going life value which takes the top step in the hierarchy of values, as well as in the system of such categories of human existence as interest and ideals, harmony, beauty, meaning and happiness of life, creative work, program and rhythm of life activity. The system of the personality's axiological orientations is formed on the basis of axiological perceptions dominating in culture. Each individual, by virtue of their innate and acquired peculiarities and under the influence of personal life circumstances, arranges them in order in their own way. However, social research shows that social groups living in similar socio-cultural conditions form hierarchically ordered structures of axiological orientations which have a nature typical of this group (Alsan, Bloom, \& Canning, 2004). Perceiving formedness of axiological orientations of young students in the field of health saving, it is possible to imagine the general orientation of its interests and ambitions, the hierarchy of individual preferences and models, purpose-oriented and motivational programs, the level of aspirations and prestigious preferences, the idea of the due and the measure ofreadiness for maintaining and improving their own health (Health in the system of axiological orientations of young students, 2010). The behavioral component of the inner picture of health represents asset of efforts, aspirations, particular actions of the person stipulated by their system of beliefs aimed at achieving subjectively significant aims with respect to health (Gurov \& Daynova, 2014). Therefore, the main peculiarity of health saving education and upbringing is the formation of students' motivational sphere, i.e. behavioral responses aimed at maintaining and improving their own health that stipulate striving to lead a healthy lifestyle, accumulate health saving potential (Zharova, 2012).

The purpose of a healthy lifestyle as a system and its systemically important factor is physical and mental health of the person. In the structure of the integrated system of a healthy lifestyle the leading role is played by the subsystem of attitudes which reflects the axiological and motivational component determining the levels of development of other subsystems and effectiveness of a healthy lifestyle in general (Pashin, 2011).

The attitude of the person to their health, on the one hand, reveals the individual's experience, and, on the other hand, has a significant influence on their behavior which is reflected not only in the value of health but in the value of a healthy lifestyle. For a person, the most important indicator of their viability is the factor of consciousness and goal-setting, as well as of axiological orientations, the most significant and independent unit in the personality structure which determines, to a significant extent, the behavior, choice of a lifestyle and social activity of the person. The axiological attitude is the conscious selective communication of the person with the objects and phenomena significant for them, reflecting the active selective position of the personality determining the individual nature of activity and particular actions. The attitudes are formed and developed in the process of accumulation and integration of all the life experience of personality. The attitudes act as a kind of 
"skeleton" of the personality's subjective world, and effectiveness of educational activityis characterized by the degree to which it ensures formation and development axiological attitudes (Pashin, 2011).

The axiological and orientational activity of students must include the following components (Zhaneev, 2013):

- Cognitive (formation of scientific knowledge of the person, the means and methods of health improvement, development of reflexive abilities — self-analysis, self-understanding, self-assessment);

- Axiological and motivational which includes the emotional constituent (assistance in choosing a personally significant system of values and ideals, formation of personal motives of health and fitness activity);

- Activity-practical (development of abilities, acquisition of competence and skills which allow to independently take care of maintenance and improvement of their own health and other people's health, ability to plan their activity);

- Diagnostic (diagnostics of levels of physical and functional fitness, health-improving competence and skills, level and nature of the attitude to health).

Based on the foregoing, the purpose of this study was to investigate the structure of students' orientation on a healthy lifestyle.

\section{Materials and Methods}

The study organization: there search work was carried out at the premises of the Institute of Pedagogics and Psychology (IPP) and the Faculty of Physical Education, Sports and Tourism (FPES and T). The pedagogical experiment enrolled 203 students of 1-2 years (junior students) and 4-5 years (senior students) at the age of 17-22, including 176 girls (87\%) and 27 young men (13\%). The "Questionnaire test for students" orientation on a healthy lifestyle" (Andreev, 2000) was used. The questions included open tasks, evaluative tests (from 10 to 1 point) and cloze tests. The following research methods were used: the study and analysis of psychological and pedagogical literature; pedagogical experiment, questionnaire survey, qualitative and quantitative analysis of data obtained, method of mathematical treatment of results.

\section{Results and Discussions}

The analysis of the data obtained showed that the highest result of orientation on a health lifestyle is only characteristic of one student among 1-2 years (picture 1). Very high level was noted for 1 junior student and 2 senior students. High level was identified for $13.7 \%$ students of $1-2$ years and $6.6 \%$ students of $4-5$ years. Most students of both groups (junior and senior students) are at the level 7 (above average) of the personality's orientation-34.7\% and 34\% respectively, most junior students having the "above average" level. And most senior students (37.7\%) show the "just above average" level. Low and very low level were not identified. The results obtained allow us to assume that in the modern system of education there is a gap between the humanistic conception and real practice, there is no consistent and continuous system of health education. The information on health is fragmentary, accidental, non-systemic, controversial and occasionally comes from incompetent people. The study of the human health phenomenon reveals striking contradictions of the human nature: 1) people want to be healthy but do little about it; 2) they have an idea of a healthy lifestyle but do nothing to improve their health.

The question of the essence and significance of health has always been the central methodological problem of many sciences. Without understanding of the concept "health" it is impossible to get an insight into axiological orientations of medicine which is intended to serve people ensuring the opportunities of the life itself in the most acceptable forms and of people themselves, as well as the place and the role of the state and the society in creation of the conditions favourable for people's life and health. Sinceoldentimes health has been the most important life value of the person, the basis of harmonious development of personality and the greatest good. In modern society "the maximum achievable level of health' is recognized as one of essential rights of the person and the people, acts as the most important condition and means, as one of ultimate purposes of social development. On the contrary, the low level of the population health is associated with the direct threat to safety of any state, with the obstacle to its social and economic progress (New paradigm of Russia's development in the XXI century, 2000). 


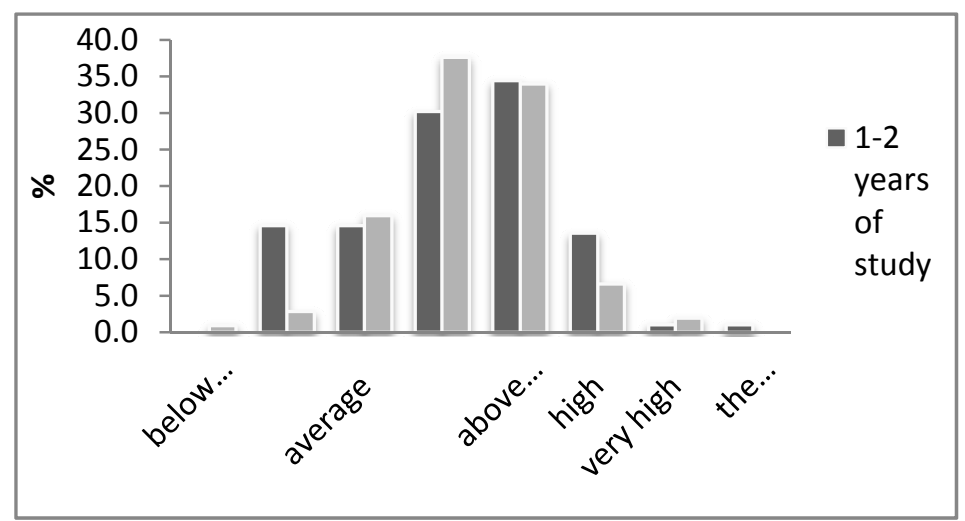

Figure 1. The level of the personality's orientation on a healthy lifestyle of students of 1-2 and 4-5 years of study

Thus, the data obtained confirm that the average results of the students' orientation on a healthy lifestyle predominate. Besides, among 1 and 2 years of study we noted higher level indexes (the highest level of the personality's orientation on a healthy lifestyle) whichcannot be found in senior students and, on the contrary, senior students have lower indexes (below average level) which were not found in junior students. We obtained the similar results earlier (Mukhina, 2010).

The index attracting most attention in the society when evaluating the level of the personality's orientation on a health lifestyle is the presence or absence of bad habits. Therefore, we considered the issues related to this problem separately in our study. Thus, according to the data obtained, answering the question, "Do you smoke?" $83 \%$ respondents among junior students and $84 \%$ of senior students gave a negative answer, the answer "seldom" was given by $16 \%$ junior students and $7 \%$ senior students, the positive answer was given by $1 \%$ and $9 \%$ respectively (picture 2). When answering the question, "Do you drink alcohol?" 57\% respondents among 1-2 years of study and $42 \%$ of senior students gave a negative answer, the answer "seldom" was used by $37 \%$ of junior students and $54 \%$ of senior students, the positive answer was given by $6 \%$ students of $1-2$ years of study and $4 \%$ students of $4-5$ years of study. The analysis of the answers to the question, "Have you ever taken any drugs?" was of particular interest. It turned out that $78 \%$ respondents among junior students and $95 \%$ among senior students had never taken any drugs (the answer "no"). $20 \%$ of students of $1-2$ years of study and $3 \%$ senior students (4-5 years of study) had taken them once. In general, based on the analysis of the results obtained, the senior students were found to be less inclined to having bad habits. 


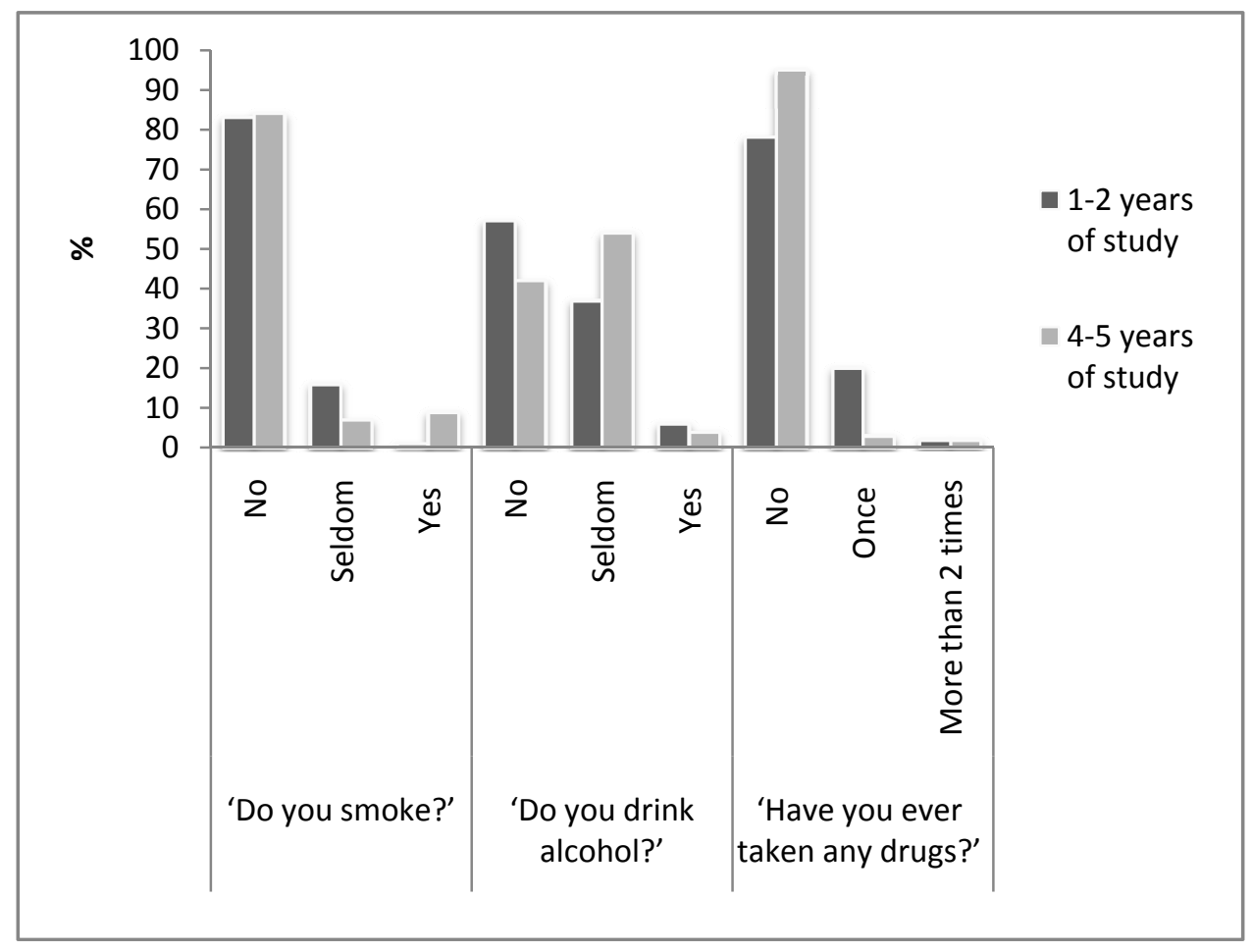

Figure 2. The students' attitude to bad habits

The definition of the concept "health" is a fundamental problem of modern biomedical science. As this concept has a lot of aspects and is stipulated by many factors, an integrated approach is required to solve it. Everybody has a good idea of the fact that "health" is a good thing, and illness is a bad thing'. It is more difficult to explain the essence of health than that of illness. The preamble of the Constitution of the WHO states that health is notonly the absence of illnesses or physical defects but also the state of full physical, mental and social welfare (the Constitution of the World Health Organization, 1946). Health is the most important characteristic of human and labor potential, human capital. This is normal state of the organism which is characterized by the optimum self-regulation, full coordination of functioning of all organs and systems, balance between the organism and the external environment without any symptoms of illness. The healthy lifestyle is an individual system of behavior and habits of each individual which ensures their necessary level of life activity and healthy longevity. The healthy lifestyle is based on both biological and social principles. Among the biological principles it is necessary to note the following: nutrition, sunlight, warmth, optimum motoring conditions, personal hygiene, cold training, seclusion and even games (predominantly in childhood). The social principles of a healthy lifestyle include the following: fruitful work, aesthetic qualities, moralities, presence of willful primacy, self-restriction ability, psychological self-regulation, eradication of bad habits, rational schedule of work and rest (Criteria for students healthy lifestyle .http://rsmu.ru/8926.html).

During the questionnaire survey we found out that $31 \%$ of senior students (4-5 years) $13 \%$ of students of the first two years gave a correct definition to the concept "health". The rest of the students give an approximate definition ( $43 \%$ of $1-2$ years of study; $42 \%$ of senior years) or have an incorrect understanding of the meaning of this concept (44\% of junior students and $27 \%$ of senior students). The concept "healthy lifestyle" is correctly defined by $24 \%$ of students of $4-5$ years of study and $10 \%$ of $1-2$ years of study; $19 \%$ and $40 \%$ respectively have no clear understanding of this concept.

Among 5-10 factors which can contribute to health improvement, most people name 5-6 factors. 57\% of students of 1-2 years of study and 73\% of students of 4-5 years of study only distinguish 5-6 factors of 10 which have an adverse effect on the human health. It should not be left unmentioned that $5 \%$ of respondents of $1-2$ years of study and $2 \%$ of senior students could not name or strongly denied the presence of the factors having an adverse effect on health.

The analysis of grading of the most valuable and significant things in life according to the ten-point scale showed that both junior and senior students gave the first three places to health, love, understanding in the family. 
Though, it is necessary to mention that senior students note material wealth as one of the five leaders.

The students were to evaluate the level of their health. The analysis of the results of health self-evaluation showed that $49 \%$ of junior students noted that they had had injuries within the last $2-3$ years, $51 \%$ often suffer from acute respiratory diseases. At the same time, $69 \%$ of respondents of this group deny that they have any infectious diseases. Besides, there is an interesting fact to note: only $29 \%$ of respondents of this group consider they suffer from chronic diseases. All this can indicate the students insufficient awareness in the field of basic medical training and healthy lifestyle. More than $55 \%$ of senior students state that they often suffer from acute respiratory diseases. However, most respondents deny that they have injuries and chronic diseases. This can be explained by the following: 1) physiological peculiarities of the organism (the work of all the systems at the optimum level in accordance with this age stage);2) adaptation to education which decreases the opportunity of influence of various stress or son students, in contrast to the first years when students are at the so-called stage of "warming-up" in the process of study in new conditions; 3 ) it should not be left unmentioned that the level of the cognitive component in the field of basic medical training and healthy lifestyle becomes slighter by the end of university studies.

\section{Conclusion}

The analysis of the results showed that the students had insufficiently digested the concept of their health. The students" understanding of the question essence and the answer completeness is also insufficient. Health is defined as one of the three most important things in the system of values but the concept of a healthy lifestyle is correctly defined only by $23 \%$ of students of $4-5$ years of study and $13 \%$ of $1-2$ years of study. We can observe the positive dynamics in the personality's orientation on a health lifestyle by 4-5 years of study. Besides, the data obtained reflect the insufficient formedness of all the components of the students' axiological and orientational activity as a cognitive constituent (low level of students' digestion of the concept of their health, insufficient understanding of the question essence and the answer completeness) and as an activity and practical constituent. The influence of genetic and environmental factors is seldom noted. The results obtained comply with the opinion that in the modern system of education there is a gap between the humanistic conception and real practice, there is no consistent and continuous system of education aimed at improving health. The information on health is fragmentary, accidental, non-systemic, controversial and occasionally comes from incompetent people. The human health manifests itself as a phenomenon which reveals striking contradictions of the human nature. On the one hand, people want to be healthy but do little about it, on the other hand, they have an idea of a healthy lifestyle but do nothing to improve their health. Our study confirms the statement made by E. A. Rakhimova (2012) about the fact that the attitude to health as a social value and a healthy lifestyle are important components of the general and professional culture of future specialists absence of which is dangerous for physical, intellectual and moral potential of the youth. It is only healthy teacher who can form a healthy generation of students. These objectives can be achieved through the reasonable combination of psycho-pedagogical and biomedical approaches, creation of the health saving environment. Health saving pedagogical technologies are not yet widely used when organizing the pedagogical process in the higher educational establishment. Moreover, the chair is experienced in using modern technologies of formation of the concepts of health and a health lifestyle, which contributes to the increase in the level of senior students' knowledge about the human being. Inclusionintheintegralsystem of health saving, development to facilities and skills of leading a healthy lifestyle are carried out by holding academic competitions, conferences, making projects, organizing internships, training courses and seminarsaimed at maintaining personal health. To form the health saving environment, we use the technologies of health improvement and overcoming negative consequences of stressful, extreme and crisis situations; assist students in the process of adaptation to the conditions of the university studies; promote a healthy lifestyle; encourage students' sporting and mass participation activity. The top priority of the tasks of formation of the axiological attitude to students' health stipulates the necessity of further studies to define the place of health in the hierarchy of universal human values.

\section{References}

Alsan, M. (2004). The Effect of Population Health on Foreign Direct Investment (p. 388). Cambridge: National Bureau of Economic Research (NBER). http://dx.doi.org/10.3386/w10596

Andreev, V. I. (2000). Health Saving Education and Upbringing (p. 267). Kazan: Centre of Innovational Technologies.

Gurov, V. N. (2014). The healthy life activity of a personality within the context of formation of its competitiveness. Innovations in education, 8, 73-85.

Health as a human value (Digital resource). (2014). Retrieved from http://biofile.ru/chel/14665.html 
Koptyug, V. A., Matrosov, V. M., \& Levashov V. K. (2000). New Paradigm of Russia's Development in the XXI Century (the integrated study of the sustainable development problems: Concepts and results) (p. 434). Moscow.

Mukhina, S. A. (2010). The diagnostics of students' orientation on a healthy lifestyle. Pedagogical diagnostics in the system of educational and pedagogical work improvement in higher and secondary education. Collection of methodological articles (pp. 125-127).

Pashin, A. A. (2011). Formation of the Axiological Attitude to Health in School Children's Physical Education (p. 228). Penza: Penza State Pedagogical University.

Rahimova, E. A. (2012). The axiological attitude of young students to health. Bulletin of the University named after P.F. Lesgaft, 9(91), 134-139.

Shabunova, A. A. (2010). Population Health in Russia: Condition and Dynamics (p. 408). Vologda: Institute of Social and Economic Development.

Zhaneev, K. E. (2013). The Formation of the Axiological Attitude to Students' Health (Digital resource). Retrieved from http://www.scienceforum.ru/2013/187/3489

Zharova, M. N. (2012). Health in the human life values (Vol. 9, pp. 57-63).

\section{Copyrights}

Copyright for this article is retained by the author(s), with first publication rights granted to the journal.

This is an open-access article distributed under the terms and conditions of the Creative Commons Attribution license (http://creativecommons.org/licenses/by/3.0/). 